\title{
Beacon - The Location-Based Service Technology to Enhance Customer Experience
}

\author{
Jiyeon Kim* \\ Department of Retailing, University of South Carolina, USA
}

*Corresponding author: Jiyeon Kim, Department of Retailing, University of South Carolina, Columbia, South Carolina, USA.

Received Date: February 15, 2020

Published Date: February 21, 2020

\begin{abstract}
In the digital mobile era of retailing, retailers can gain an opportunity to have a better understanding of their customers and closer connections with them than ever before. Mobile engagement enables retailers to develop and implement a very effective "hyper-local" proximity marketing strategies by obtaining consumer data that provide more in-depth insight into understanding their behaviors. Real-time on-site communications with a customer are vital to engage customers and increase sales. Thus, this paper discusses the applications of Location-based Service Technologies in beauty and fashion, health, tourism, and sports and entertainment industries. Managerial implications and challenges of using location-based services are also discussed.

Keywords: Location-based technology; Marketing; Hyper customization; Customer experience; Omnichannel retailing; Beacon
\end{abstract}

\section{Introduction}

The rapid advances in digital and mobile communication technologies have given retailers an opportunity to have a better understanding of their customers and closer connections with them than ever before. Being able to identify an individual consumer in real-time locations and deliver highly personalized messages that are relevant to the targeted consumer when needed is essential for retailers to attract them into their stores and encourage them to make a purchase [1]. Micro-targeting of the potential customers in the proximity of the store can be done using location-based technologies, such as Beacon [2].

First introduced by Apple Inc. in 2013 as iBeacon, Beacon refers to small transmission hardware that is Bluetooth enabled and can be placed anywhere in the store premises [3]. Beacons transmit BLE signals to reach consumers' smartphones with Bluetooth on in a 50-foot range within the retail store and to push notifications into the phones. Users need to download a specific app on a mobile phone that supports tracking technology and have Bluetooth turned on and activate Location Services in order to have a beacon communicate with their smartphones. Upon opting in, consumers can receive the information regarding the nearby brand/store/ product on their phones (e.g., merchandise descriptions, availability, recommendations, locations, exclusive promotional offers, loyalty programs, special events, in-store navigations, speedy checkout, and payment, etc.) $[4,5]$.

Although NFC (near field communication) and GPS geofencing technologies have similar location-focused purposes and properties, Beacons are capable of being "hyper-local," more precisely locationpinpointed than GPS geofencing, and communication-able with a variety of smartphones (Android and iOS) without an NFC chip in a broader range [6]. While others' main functions are customer/ product tracking and identification, Beacons can also "push" targeted content to relevant individuals. The push messages can be highly individualized and customized to the individual customer's likings, preferences, and needs, thus enhancing the individual's instore shopping experience.

This type of mobile engagement (using the ability to generate location-sensitive, highly relevant and personalized offers) enables retailers to develop and implement a very effective "hyper-local" 
proximity marketing strategies by obtaining the consumer data (e.g., where they are and go, what they do and not do at the exact moment, and how long they stay) that provide deeper insight into understanding their behaviors. With this type of technology, a retailer can deliver the message to the customer at the precise moment with the relevant content that will trigger the action (or at least spark his interests of being engaged into shopping activities at the exact moment at the desired location). This new way of connecting with customers can promise endless possibilities for retailers with real-time on-site customer engagement. Thus, it is important to understand the complexity of what this type of technology can do to successfully implement proximity marketing aided by mobile devices and location-based services [7].

\section{Discussion}

\section{Applications of location-based service technologies}

Beauty and fashion industry: In addition to the number of things Beacon-powered messages can do to enhance in-store shopping experience mentioned above, Beacons can also help the customer find the product of his interest by giving him the info of the product on display when walking by and lets him know the exact location of that product. Further, a virtual product display can be changed in a customized way based on the individual's preferences and purchase patterns when he approaches. This kind of individualization can be done by the collection of data in his phone - information search, shopping patterns, social media postings and activities, and locations he visited. A cosmetic specialty retailer, Sephora, has been using Beacons (for personalized alerts and loyalty programs) in conjunction with Augmented reality to make the shopping experience more personal and enjoyable. For example, a customer can hover their mobile devices over nine participating brands, such as Kat von D and Laura Mercier, that are featured in display cases and store windows. Beacon triggered push notifications can be potentially used for price matching, where the offer is presented to a shopper at the most crucial point of decision making. This may help brick-and-mortar retailers avoid consumers "showrooming" practices, where consumers examine the products in-store and go online or mobile to find the best price deal, which can hinder in-store purchase behaviors [3]. The price matching feature can increase in-store sales while increasing consumers' perception toward monetary, convenience, and epistemic values $[8,9]$. Brands may use this type of data for dynamic pricing to beat their competition.

Healthcare industry: Health Media Network plans to work with Gimbal to deploy beacons at HMN's digital displays in the 12,000 medical centers for more individualized communications between patients and wellness brands [10]. Rite Aid began working with in Market to deploy Beacons to its 4,600 U.S. stores for a similar purpose [10]. Location-based service technology devices will be able to communicate with wearable technologies to get customer vitality info along with other data to make customized product recommendations along with other wellbeing and necessary pre- cautious information regarding diseases and care information when an individual enters a pharmacy store.

Tourism industry: Beacons can be used to enhance consumers' travel experience. For example, Miami International Airport has deployed 500 plus Beacons that can push notifications regarding departures, delays, and gate assignments, and turn-byturn navigation guides to their gates to the traveling consumers' smartphones [11]. The airport is planning to upgrade the Beaconpowered app for more personalized travel assistance by pushing messages regarding the traveler's destination tourist attraction, lodging, and restaurant info to enhance the travel experience [11]. At the destination, Beacons can be used by hotels and resorts for customer relationship management of valued loyal customers by recognizing them and knowing exactly what they like. For example, Starwood Hotels \& Resorts use Beacons to create a more personalized guest experience [12]. Concierges can identify a frequent guest, greet arriving them by name (perhaps treat them with coffee to their likings), and let housekeeping know when guests are arriving or still in the room, making sure everything is set to their likings and preferences (e.g., keyless entry, accelerated check in-out, in-room controls and arrangements, F\&B, blue dot navigation, concierge assistance).

Sports and entertainment industry: Beacons have become increasingly popular in the sports and entertainment industry successfully in engaging attendees at sports arenas and events. Ninety-three percent of all MLB stadiums in the US have deployed beacons, along with $75 \%$ of all NFL stadiums, $53 \%$ of all NBA arenas, and $47 \%$ of all NHL arenas. Beacons help sports teams enhance loyalty, gather data about attendees, and provide an entry point for fans to become more digitally engaged [13]. In addition, beacons are used to promote merchandise and food sales by sending pushnotifications before/during/after the live games. For example, in its first season using beacons in 2014-2015, NBA-affiliated Golden State Warriors saw average transaction volume across items (including merchandise, food purchases, and seat upgrades) rose $87 \%$ from the prior season. The Orlando Magic, an NBA team, reported average app adoption among fans reached $30 \%$ after it deployed beacons, compared to the industry standard of $5 \%$. The team also experienced an increase of over $\$ 1$ million in ticket sales due to beacon engagement and messages during the same season (BI Intelligence, 2016).

\section{Conclusion}

\section{Managerial implications and challenges}

The location-based service technologies can function in enhancing consumers' experience only when an individual decides to opt-in and grants the access of their personal information and their real-time locations to the service providers and the retailers who will use the data. Although the purpose of collecting the behavioral data from tracking a consumer's behavior, interests, search, and location patterns is to be analyzed for better catering customers 
with a truly personalized, relevant, and engaging experience, this may be viewed as an intrusion of privacy [14]. However, given that individual privacy decision making is often done as an exchange of personal information in return for consumer benefits that increase the value of shopping $[15,16]$, these concerns can be addressed in the efficacy of three privacy intervention approaches - compensation (e.g., financial and convenience benefits), industry self-regulation, and government regulation [17]. In this way, consumers' perceived value from the shopping experience aided by the Beacon technologies will increase, which will ease up their privacy concerns [12]. We expect another challenge will be data security. Potential breach of confidentiality, unintended disclosure of personally identifiable information, financial information, and the real-time location can result in identity theft and threaten the individuals' safety. In the following section, we discuss the legal concerns of digitization, including privacy rights, data security, and potential liability regarding the collection and the use of highly sensitive personal data for creating customized products and communications.

\section{Acknowledgement}

None.

\section{Conflict of Interest}

Authors declare no conflict of interest.

\section{References}

1. Neslin SA, Jerath K, Bodapati A, Bradlow ET, Deighton J, et al. (2014) The interrelationships between brand and channel choice. Marketing Letters 25(3): 319-330.

2. Sichitiu ML, Ramadurai V (2004) Localization of wireless sensor networks with a mobile beacon. IEEE International Conference on Mobile Ad-hoc and Sensor Systems: 174-183.

3. Rapp A, Baker TL, Bachrach DG, Ogilvie J, Skinner-Beitelspacher L
(2015) Perceived customer showrooming behavior and the effect on retail salesperson self-efficacy and performance. Journal of Retailing 91(2): 358-369.

4. Beacontastic (2015) The A to $\mathrm{Z}$ of proximity marketing with Beacons.

5. Dyke DV (2017) The voice payment report; The next major interface for payments. Business Insider.

6. Zou H, Jiang H, Luo Y, Zhu J, Lu X, et al. (2016) Blue Detect: An iBeaconEnabled Scheme for Accurate and Energy-Efficient Indoor-Outdoor Detection and Seamless Location-Based Service. Sensors 16(2): 268.

7. O'Donnell B (2017) The next looming battle in the tech world will be based around digital assistants. Recode.

8. Natarajan T, Balasubramanian SA, Kasilingam L (2017) Understanding the intention to use mobile shopping applications and its influence on price sensitivity. Journal of Retailing and Consumer Services 37: 8-22.

9. Pura M (2005) Linking perceived value and loyalty in location-based mobile services. Managing Service Quality 15(6): 509-538.

10. Kaplan D (2016) Gimbal rolls out Beacons to 12,000 doctors' offices with Health Media Network. HMN News.

11. Garcia M (2016) Miami airport becomes one of the first to connect consumers with Beacons. Skift.

12. Malik N (2014) How hotels can use Beacons to enhance guest experiences. Beacontastic.

13. Hirst R (2016) Siri, Echo and Google Home: are digital assistants the future of the office? Digital Business.

14. Junglas IA, Johnson NA, Spitzmüller C (2008) Personality traits and concern for privacy: An empirical study in the context of locationbased services. European Journal of Information Systems 17(4): 387402.

15. Laufer RS, Wolfe M (1977) Privacy as a concept and a social issue: A multidimensional developmental theory. Journal of Social 33(3): 2242.

16. Stone EF, Stone DL (1990) Privacy in organizations: Theoretical issues, research findings, and protection mechanisms. Research in Personnel and Human Resources Management 8(3): 349-411.

17. Xu H, Teo HH, Tan BC, Agarwal R (2009) The Role of Push-Pull Technology in Privacy Calculus: The Case of Location-Based Services. Journal of Management Information Systems 26(3): 135-174. 